\title{
Integrating food webs with metabolic networks: modeling contaminant degradation in marine ecosystems
}

\author{
Georg Basler $^{1}$ and Evangelos Simeonidis ${ }^{2,3}$ * \\ ' Department of Environmental Protection, Estación Experimental del Zaidín Consejo Superior de Investigaciones Científicas, Granada, Spain \\ ${ }^{2}$ Luxembourg Centre for Systems Biomedicine, University of Luxembourg, Esch-sur-Alzette, Luxembourg \\ ${ }^{3}$ Institute for Systems Biology, Seattle, WA, USA \\ ${ }^{*}$ Correspondence: evangelos.simeonidis@uni.lu \\ Edited by: \\ Damien Eveillard, Université de Nantes, France \\ Reviewed by: \\ Lionel Guidi, Centre National de la Recherche Scientifique, France
}

Keywords: flux balance analysis, ecosystem modeling, food webs, biodegradation, PCBs, marine ecosystems, network analysis, genome-scale metabolic modeling

\section{A commentary on}

Bioremediation in marine ecosystems: a computational study combining ecological modeling and flux balance analysis

by Taffi, M., Paoletti, N., Angione, C., Pucciarelli, S., Marini, M., and Liò, P. (2014). Front. Genet. 5:319. doi: 10.3389/fgene.2014.00319

The seas are continuously pervaded by a broad range of contaminants entering the marine environment from polluted soils, the atmosphere, sewage, water transport or river streams (Shahidul Islam and Tanaka, 2004). Organic pollutants are of particular concern, because of their tendency to accumulate in specific organisms, thus threatening both ecosystem stability and human health (Fleming et al., 2006; Johnston and Roberts, 2009). Among those, polychlorinated biphenyls (PCBs) are synthetic compounds produced by the chemical industry and found throughout global environments (Beyer and Biziuk, 2009). Due to their hydrophobicity, PCBs accumulate in the lipids of marine species, leading to bioaccumulation predominantly at higher trophic levels (Perugini et al., 2004). On the other hand, PCBs can be degraded by the sequential anaerobic and aerobic metabolic processes of microorganisms (Borja et al., 2005). Consequently, the accumulation and fate of these pollutants within ecosystems depend not only on their uptake by and transfer among marine species, but also on microbial biodegradation. The biostimulation of degrading bacteria or their insertion (bioaugmentation) at contaminated sites may represent a promising strategy for bioremediation (Tyagi et al., 2011).

Biomass transfer among species of a food web can be modeled using allometric scaling rules describing body size, consumption and metabolism (Yodzis and Innes, 1992; Berlow et al., 2009). Similarly, the flow of contaminants through a food web can be estimated by mass-balance modeling of chemical transfer and adsorption (Wania and Mackay, 1999; Arnot and Gobas, 2004; Breivik et al., 2007; Nichols et al., 2009; Taffi et al., in press). Such modeling approaches can be complemented by measurements of contaminant concentrations (Kelly et al., 2007). Recently, a food web representing the major ecological groups of the Adriatic Sea and their predator-prey interactions (Coll et al., 2007) was integrated with PCB concentration data obtained from an extensive literature review (Taffi et al., in press). The resulting model allowed prediction of the flow rates of PCBs among ecological groups and reproduced the finding that PCBs accumulate mostly in species at higher trophic levels and with lower total biomass. Further, the model allowed estimation of the fate of contaminants, such as their bioaccumulation in marine species.

The described efforts facilitated generic estimations of contaminant flows in ecosystems, but largely neglected the contribution of microorganisms to pollutant degradation. Specifically, PCBs can be dechlorinated and degraded by a range of bacteria (Borja et al., 2005). Thus, biodegradation may be an important factor for the persistence of a pollutant within an ecosystem and, moreover, may provide hints for bioremediation strategies based on the aforementioned bacteria. The uptake, degradation and excretion of compounds by microorganisms can be predicted from the knowledge of their metabolic capabilities using constraintbased approaches (Bordbar et al., 2014). Today, detailed metabolic reconstructions are available for a broad range of organisms (Monk et al., 2014), including several bacteria known for their bioremediation capabilities, such as Geobacter spp. (Mahadevan et al., 2011), Shewanella oneidensis (Fredrickson et al., 2008), and Pseudomonas putida (Nogales et al., 2008); and new reconstructions for more organisms are published regularly. Thus, an intriguing challenge is the combination of ecological and metabolic modeling approaches to integrate population-level simulations of ecosystems with cellular modeling of microbial metabolism, similar to the previous integration of reactive transport models with metabolic models (Fang et al., 2011).

Taffi et al. (2014) have recently integrated a comprehensive food web of the Adriatic Sea with PCB concentration data and a metabolic model of $P$. putida. First, the authors conducted an extensive literature review to complement a food web reconstruction (Coll et al., 2007) with data of PCB concentrations among marine species (Taffi et al., in press). Next, linear inverse modeling was 
used to infer unknown contaminant flows and concentrations based on the mass balance principle. Finally, the ecological network was integrated with the genomescale metabolic network of $P$. putida for constraint-based simulation of microbial PCB degradation. The study integrated two methodologically similar modeling approaches within a reaction-based ecological/microbial network representation, relying on the parallels between representing PCB concentrations and flows on the ecosystem level, and metabolite concentrations and reaction fluxes on the microbial cellular level. Therein, marine species groups resemble the representation of metabolites, while contaminant flows are modeled as reactions. This approach enabled the seamless integration of ecological and metabolic modeling techniques, providing the basis for multi-scale simulations of ecosystems.

The modeling approach was used to predict the influence of different microbial bioremediation strategies on the fate and distribution of PCBs in marine species of the Adriatic Sea. The effect of varying oxygen levels on microbial PCB degradation revealed a tradeoff between PCB uptake and growth of $P$. putida. Further, the impact of different bioremediation scenarios on global and local network indices was assessed. Importantly, the generality of the proposed approach facilitates the integration of measured data, the incorporation of established techniques from ecological and metabolic modeling and the direct application of the methodology to other ecological and microbial networks. Thus, it can be used to guide the selection of appropriate bacteria and consortia (Thompson et al., 2005), or the design of genetically engineered bacteria for bioremediation (Singh et al., 2011). The approach will stimulate new developments in ecological modeling and offer insights into the multi-level interplay among ecosystems, microbial networks and biodegradation.

\section{ACKNOWLEDGMENTS}

We thank Alejandro Acosta-González for critical comments on the manuscript. Georg Basler is supported by a Marie Curie Intra European Fellowship within the 7th European Community Framework Programme, ERC grant agreement number 329682. Evangelos Simeonidis is supported by the Luxembourg Centre for Systems Biomedicine.

\section{REFERENCES}

Arnot, J. A., and Gobas, F. A. P. C. (2004). A food web bioaccumulation model for organic chemicals in aquatic ecosystems. Environ. Toxicol. Chem. 23 , 2343-2355. doi: 10.1897/03-438

Berlow, E. L., Dunne, J. A., Martinez, N. D., Stark, P. B., Williams, R. J., and Brose, U. (2009). Simple prediction of interaction strengths in complex food webs. Proc. Natl. Acad. Sci. U.S.A. 106, 187-191. doi: 10.1073/pnas.0806823106

Beyer, A., and Biziuk, M. (2009). Environmental fate and global distribution of polychlorinated biphenyls. Rev. Environ. Contam. Toxicol. 201, 137-158. doi: 10.1007/978-1-4419-0032-6_5

Bordbar, A., Monk, J. M., King, Z. A., and Palsson, B. Ø. (2014). Constraint-based models predict metabolic and associated cellular functions. Nat. Rev. Genet. 15, 107-120. doi: 10.1038/nrg3643

Borja, J., Taleon, D. M., Auresenia, J., and Gallardo, S. (2005). Polychlorinated biphenyls and their biodegradation. Process. Biochem. 40, 1999-2013. doi: 10.1016/j.procbio.2004.08.006

Breivik, K., Sweetman, A., Pacyna, J. M., and Jones, K. C. (2007). Towards a global historical emission inventory for selected PCB congeners - A mass balance approach: 3. An update. Sci. Total Environ. 377, 296-307. doi: 10.1016/j.scitotenv.2007. 02.026

Coll, M., Santojanni, A., Palomera, I., Tudela, S., and Arneri, E. (2007). An ecological model of the Northern and Central Adriatic Sea: analysis of ecosystem structure and fishing impacts. J. Mar. Syst. 67, 119-154. doi: 10.1016/j.jmarsys.2006.10.002

Fang, Y., Scheibe, T. D., Mahadevan, R., Garg, S., Long, P. E., and Lovley, D. R. (2011). Direct coupling of a genome-scale microbial in silico model and a groundwater reactive transport model. J. Contam. Hydrol. 122, 96-103. doi: 10.1016/j.jconhyd.2010.11.007

Fleming, L. E., Broad, K., Clement, A., Dewailly, E., Elmir, S., Knap, A., et al. (2006). Oceans and human health: emerging public health risks in the marine environment. Mar. Pollut. Bull. 53, 545-560. doi: 10.1016/j.marpolbul.2006. 08.012

Fredrickson, J. K., Romine, M. F., Beliaev, A. S., Auchtung, J. M., Driscoll, M. E., Gardner, T. S., et al. (2008). Towards environmental systems biology of Shewanella. Nat. Rev. Microbiol. 6, 592-603. doi: 10.1038/nrmicro1947

Johnston, E. L., and Roberts, D. A. (2009). Contaminants reduce the richness and evenness of marine communities: a review and meta-analysis. Environ. Pollut. 157, 1745-1752. doi: 10.1016/j.envpol.2009.02.017

Kelly, B. C., Ikonomou, M. G., Blair, J. D., Morin, A. E., and Gobas, F. A. P. C. (2007). Food webspecific biomagnification of persistent organic pollutants. Science 317, 236-239. doi: 10.1126/science. 1138275

Mahadevan, R., Palsson, B. Ø., and Lovley, D. R. (2011). In situ to in silico and back: elucidating the physiology and ecology of Geobacter spp. using genome-scale modelling. Nat. Rev. Microbiol. 9, 39-50. doi: 10.1038/nrmicro2456

Monk, J., Nogales, J., and Palsson, B. Ø. (2014). Optimizing genome-scale network reconstructions. Nat. Biotechnol. 32, 447-452. doi: 10.1038/nbt.2870

Nichols, J. W., Bonnell, M., Dimitrov, S. D., Escher, B. I., Han, X., and Kramer, N. I. (2009). Bioaccumulation assessment using predictive approaches. Integr. Environ. Assess. Manag. 5, 577-597. doi: 10.1897/IEAM 2008-088.1

Nogales, J., Palsson, B. Ø., and Thiele, I. (2008). A genome-scale metabolic reconstruction of Pseudomonas putida KT2440: iJN746 as a cell factory. BMC Syst. Biol. 2:79. doi: 10.1186/1752-0509-2-79

Perugini, M., Cavaliere, M., Giammarino, A., Mazzone, P., Olivieri, V., and Amorena, M. (2004). Levels of polychlorinated biphenyls and organochlorine pesticides in some edible marine organisms from the Central Adriatic Sea. Chemosphere 57, 391-400. doi: 10.1016/j.chemosphere.2004.04.034

Shahidul Islam, M., and Tanaka, M. (2004). Impacts of pollution on coastal and marine ecosystems including coastal and marine fisheries and approach for management: a review and synthesis. Mar. Pollut. Bull. 48, 624-649. doi: 10.1016/j.marpolbul.2003.12.004

Singh, J. S., Abhilash, P. C., Singh, H. B., Singh, R. P., and Singh, D. P. (2011). Genetically engineered bacteria: an emerging tool for environmental remediation and future research perspectives. Gene 480, 1-9. doi: 10.1016/j.gene.2011.03.001

Taffi, M., Paoletti, N., Angione, C., Pucciarelli, S., Marini, M., and Liò, P. (2014). Bioremediation in marine ecosystems: a computational study combining ecological modeling and flux balance analysis. Front. Genet. 5:319. doi: 10.3389/fgene.2014.00319

Taffi, M., Paoletti, N., Liò, P., Pucciarelli, S., and Marini, M. (in press). Bioaccumulation modelling and sensitivity analysis for discovering key players in contaminated food webs: the case study of PCBs in the Adriatic Sea. Ecol. Modell. doi: 10.1016/j.ecolmodel.2014.11.030

Thompson, I. P., Van Der Gast, C. J., Ciric, L., and Singer, A. C. (2005). Bioaugmentation for bioremediation: the challenge of strain selection. Environ. Microbiol. 7, 909-915. doi: 10.1111/j.1462-2920.2005.00804.x

Tyagi, M., Da Fonseca, M. M. R., and De Carvalho, C. C. C. R. (2011). Bioaugmentation and biostimulation strategies to improve the effectiveness of bioremediation processes. Biodegradation 22, 231-241. doi: 10.1007/s10532-010-9394-4

Wania, F., and Mackay, D. (1999). The evolution of mass balance models of persistent organic pollutant fate in the environment. Environ. Pollut. 100, 223-240. doi: 10.1016/S0269-7491(99) 00093-7

Yodzis, P., and Innes, S. (1992). Body size and consumer-resource dynamics. Am. Nat. 139, 1151-1175. doi: 10.1086/285380

Conflict of Interest Statement: The authors declare that the research was conducted in the absence of any commercial or financial relationships that could be construed as a potential conflict of interest. 
Received: 03 December 2014; accepted: 15 January 2015; published online: 03 February 2015.

Citation: Basler G and Simeonidis E (2015) Integrating food webs with metabolic networks: modeling contaminant degradation in marine ecosystems. Front. Genet. 6:20. doi: 10.3389/fgene.2015.00020
This article was submitted to Systems Biology, a section of the journal Frontiers in Genetics.

Copyright ( () 2015 Basler and Simeonidis. This is an open-access article distributed under the terms of the Creative Commons Attribution License (CC BY). The use, distribution or reproduction in other forums is permitted, provided the original author(s) or licensor are credited and that the original publication in this journal is cited, in accordance with accepted academic practice. No use, distribution or reproduction is permitted which does not comply with these terms. 